ISSN: 2637-4676

\title{
Musings on Conservation Agriculture
}

\author{
Samuel I Haruna* \\ School of Agriculture, Middle Tennessee State University, USA
}

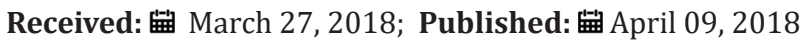

*Corresponding author: Samuel I Haruna, School of Agriculture, Middle Tennessee State University, USA

\section{Editorial}

The dawn of the $21^{\text {st }}$ century has witnessed an explosion in the already increasing advances in technology and knowledge; observation of the Higgs particle in the large Hadron collider, determination of the age and size of the universe by the Hubble telescope and the amount of transistors that can be placed on a single chip, amongst others. Thus, it is very easy and convenient to measure the advancement of the human race on these achievements alone, ignoring other important aspects that equally contribute to our survival: Agriculture.

Homo sapiens sapiens was predominantly hunter-gatherers during the first few hundred years. As time went on, the mobile lifestyle of hunting, gathering and scavenging gave way to a more sedentary one; agriculture. Since then, majority of the human needs for food have been largely derived from cultivating the field. We tinkered with agriculture and developed tools, primitive as they might be, to improve crop production. We used sticks to bore holes for seed incorporation. This led to the development of the plow and later the heavy tillage equipment that we are currently familiar with. We studied soil microorganisms and can now use them to boost crop productivity. We are now able to breed needed traits into cash crops to improve productivity on less productive soils. All these efforts are also indicators of human advancement.

Despite this technological, medical, and agricultural advancement, we are still faced with certain problems. Not too long ago, 99\% of humans were involved in agriculture. Currently, an approximated $1 \%$ of humans are responsible for feeding and nourishing the remaining 99\%. This huge demand for food, feed and fiber naturally puts pressure on farmers and producers alike. This is further exacerbated by the rising human population and the increasing average age of farmers. How do we, as specie, respond to these challenges?.

The natural response will be to increase agricultural activities; plow more fields, raise more livestock, and trees. However, this 'brute force' approach has some attendant problems. The soil is a finite resource. Only about $29 \%$ of the earth surface is solid and this includes rocks, and non-arable lands such as deserts, wetlands, saline and acidic soils. Thus, only about 1.5 billion ha of land is currently being used for crop production. To increase agricultural productivity, intensive cultivation is the normal recourse.

In order to increase food production on a finite resource, deforestation, wetland drainage, and intensive cultivation are the natural resorts. In his book 'Dirt: The Erosion of Civilizations', David Montgomery outlined the impact of poor land management on several civilizations: from the Roman Empire to Easter Island, from Mesopotamia to Greece, the demise of these once great societies can be traced to the mismanagement of their soil. Nearly a century ago, the 'Dust Bowl' reminded us how important soil and crop management is. It forced us to pay better attention to agriculture; conservation and sustainable agriculture. Since then, we have diversified our portfolio by advocating for reduced/minimal tillage, crop rotation, incorporation of cover crops into crop production cycles. These, along with availability of synthesized plant nutrients, and improvement in crop physiology have enabled producers to provide food and nourishment.

As the human population continues to rise to the projected 9 billion by 2050, there are concerns about food security. At the current rate, about 800 million people across the world still go to bed hungry every night. The projected 9 billion people will require between 60 - 80\% increases in the current crop production by 2050 .

It is imperative now, more than ever before in the history of our species, to continue to advocate for and implement conservation agriculture practices. We need to continue to investigate ways of improving crop production while minimizing the environmental impact. We need to avoid mechanical soil disturbance as much as possible, avoid soil compaction, improve residue addition to further build-up soil organic matter, maintain balanced soil nutrient 
levels, and ensure that the soil is not left bare. Thus, this is a call to advocacy, research, and implementation of better agricultural management practices. Our continued existence may not be owed to better communication or better understanding of the universe alone, but on the availability of food, feed and fiber through the practice of sustainable agriculture.

\section{CC (i) This work is licensed under Creative}

To Submit Your Article Click Here: $\quad$ Submit Article

DOI: 10.32474/CIACR.2018.01.000125

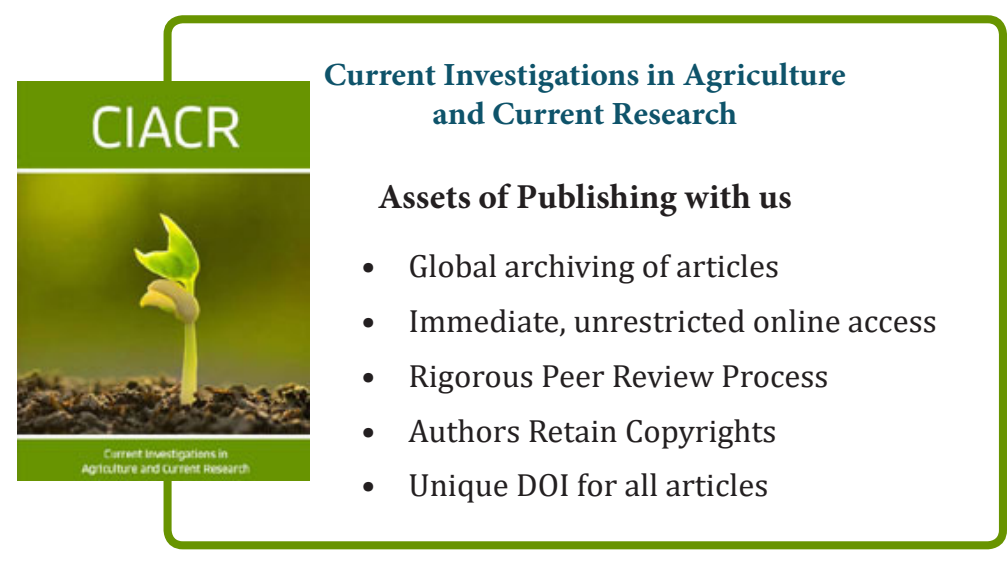

